\title{
Molecular characterization of cathepsin B from Clonorchis sinensis excretory/secretory products and assessment of its potential for serodiagnosis of clonorchiasis
}

Wenjun Chen ${ }^{1,2}$, Xiaoyun Wang ${ }^{1,2}$, Xuerong Li ${ }^{1,2}$, Xiaoli Lv ${ }^{1,2}$, Chenhui Zhou ${ }^{1,2,3}$, Chuanhuan Deng ${ }^{1,2}$, Huali Lei ${ }^{1,2}$, Jingtao Men ${ }^{1,2}$, Yongxiu Fan ${ }^{1,2}$, Chi Liang ${ }^{1,2}$ and Xinbing $\mathrm{Yu}^{1,2^{*}}$

\begin{abstract}
Background: Cathepsin cysteine proteases play multiple roles in the life cycle of parasites such as food uptake, immune invasion and pathogenesis, making them valuable targets for diagnostic assays, vaccines and drugs. The purpose of this study was to identify a cathepsin B of Clonorchis sinensis (CsCB) and to investigate its diagnostic value for human helminthiases.

Results: The predicted amino acid sequence of the cathepsin B of C. sinensis shared 63\%, 52\%, 50\% identity with that of Schistosoma japonicum, Homo sapiens and Fasciola hepatica, respectively. Sequence encoding proenzyme of CsCB was overexpressed in Escherichia coli. Reverse transcription PCR experiments revealed that CSCB transcribed in both adult worm and metacercaria of C. sinensis. CSCB was identified as a C. sinensis excretory/secretory product by immunoblot assay, which was consistent with immunohistochemical localization showing that CSCB was especially expressed in the intestine of $C$. sinensis adults. Both ELISA and western blotting analysis showed recombinant CsCB could react with human sera from clonorchiasis and other helminthiases.
\end{abstract}

Conclusions: Our findings revealed that secreted CsCB may play an important role in the biology of C. sinensis and could be a diagnostic candidate for helminthiases.

\section{Background}

Clonorchis sinensis is the causative agent of clonorchiasis, a chronic liver infection of human acquired through consumption of raw or undercooked fish and shrimps with infectious metacercariae. Clonorchiasis is endemic in Asian countries and over 35 million people globally are infected C. sinensis, including an estimated 15 million in People's Republic of China [1]. Recently, this infection has emerged in non-endemic regions and developed countries following growing international markets, improved transportation systems and demographic changes such as population movements [2]. C. sinensis adults reside chronically in the biliary tract and cause periductal inflammation, fibrosis, pyogenic

\footnotetext{
* Correspondence: yuhxteam@163.com

'Department of Parasitology, Zhongshan School of Medicine, Sun Yat-sen

University, Guangzhou 510080, People's Republic of China

Full list of author information is available at the end of the article
}

cholangitis, biliary calculi, cholecystitis, liver cirrhosis and pancreatitis [3]. Like Opisthorchis viverrini, C. sinensis is one of the direct causes of cholangiocarcinoma announced by the International Agency for Research on Cancer (IARC) in 2009 [4]. It is important to take some measures to control clonorchiasis due to its public health threat. Until now, the main prevention and control strategies for this parasite are treatment of individual patients with praziquantel, and interrupting transmission at the intermediate host level [5]. However, there have been little effective measures to prevent this neglected tropical disease [6].

Cysteine proteinase is ubiquitous in all species [7-9]. In parasites, cysteine proteases have attracted much attention for their essential roles in parasite physiology as well as in host-parasite interactions through their modulation of various pathobiological events, including host tissue invasion, nutrient uptake, host immune

\section{C) Biomed Central}


evasion and molting [10-13]. Research has been conducted to characterize the biochemical properties and pathophysiological roles of cysteine proteases from trematode parasites. The essential roles of cysteine proteases in parasite survival or growth make them attractive targets for vaccines or chemotherapeutic agents [14-16]. Several genes encoding C. sinensis cysteine proteases have been identified and partially characterized [17-19]. Lee et al. [20] reported that cathepsin F-like cysteine protease of $C$. sinensis is a good vaccine candidate against clonorchiasis. Li et al. [21] found that endogenous cysteine proteases of $C$. sinensis metacercariae are probably involved in the excystment process. Kang et al. [22] indicated that partially purified cysteine protease from excretory/secretory products (ESP) of C. sinensis adults exhibited significant cytotoxic effects against cultured cells. ESP of parasites have attracted more attention for their significant roles in the diagnosis, vaccine, drug target and host-parasite interactions etc. In vitro biochemical studies have predicted that ESP from liver flukes have definitive roles in feeding behavior, detoxification of bile components and immune evasion [23]. Ju et al. [18] have identified legumain from ESP as a serodiagnostic antigen of clonorchiasis. In addition, several genes encoding $C$. sinensis cysteine proteases have also been identified and their value as diagnostic antigens for clonorchiasis was investigated $[24,25]$. However, little is known about cathepsin B (CB) in $C$. sinensis except five distinct sequences deposited in Genbank.

As members of the cysteine protease family, cathepsins have been assayed in the serodiagnosis of both human and animal in parasite infections. Cornelissen et al. [26] reported a specificity of $75.3 \%$ in naturally infected cattle using Fasciola hepatica cathepsin L as coating antigen. Carnevale et al. [27] found that recombinant pro-cathepsin-L was $100 \%$ specific in the diagnosis of human F. hepatica infection. Sripa et al. [28] indicated that $O v$-CB-1 was acceptable in ELISA for the serodiagnosis of human opisthorchiasis with $67 \%$ and $81 \%$ of sensitivity and specificity, respectively. To find out whether $\mathrm{CB}$ could be applied for serodiagnosis in C. sinensis infection, we identified a gene encoding cathepsin $\mathrm{B}$ of $C$. sinensis (Cs CB) and investigated its diagnostic value for human helminthiases.

\section{Results}

\section{Sequence analysis of CsCB gene sequence}

The complete coding sequence of $C s \mathrm{CB}$ is comprised of 1,020 bp encoding a putative protein of 339 amino acids with a predicted molecular mass of $37.9 \mathrm{kDa}$ and an isoelectric point of 5.32. The ORF consists of a hydrophobic signal peptide at the $\mathrm{N}$-terminus, followed by a proregion of between 70 and $71 \mathrm{AA}$ and a mature protease sequence. BLASTx showed that it shared 63\%, 52\%, 50\% and 53\% identity with CB of Schistosoma japonicum, Homo sapiens, F. hepatica and Echinococcus multilocularis, respectively. Highly conserved residues of the catalytic triad $\left(\mathrm{Cys}_{116}, \mathrm{His}_{285}\right.$ and $\left.\mathrm{Asn}_{305}\right)$ as well as the Gln could be searched in this sequence. The putative protein contained an occluding loop that is the signature of cathepsin Bs and a haemoglobinase motif which is shared by helminth blood-feeders (Figure 1).

\section{Cloning, expression and purification of recombinant CsCB $(r C s C B)$ in $E$. coli}

The recombinant pET-28a(+) plasmid containing the $\mathrm{CB}$ gene coding region (signal peptide removed) was confirmed by digestion with restriction enzyme. DNA sequencing revealed that the construct was correct with $6 \times$ His tag at the $\mathrm{N}$ terminus of the recombinant protein. The recombinant $C s \mathrm{CB}$ was expressed in inclusion bodies in E. coli. SDS-PAGE showed that the molecular mass of fusion protein was about $40 \mathrm{kDa}$, which was in correspondence with the predicted $39.2 \mathrm{kDa}$ (including 34 amino acids of vectors). After purification and renaturation, the concentration of the recombinant protein was about $0.25 \mathrm{mg} / \mathrm{ml}$ (Figure 2A).

\section{Identification of CsCB as ESP by western blotting}

Rat anti-rCsCB antibody titers were higher than 1:102,400 as determined by ELISA. In western blotting assay, both C. sinensis-infected rat serum and anti-CsCB rat serum could react with the $C s C B$ while the normal rat serum could not. Comparing with the control group, sera from rats immunized with total ESP could recognize $\mathrm{Cs} C \mathrm{CB}$. In addition, ESP has been shown to react with anti-CsCB rat serum (data not shown). The results above indicated that $\mathrm{Cs} \mathrm{CB}$ was a component of ESP (Figure 2B).

\section{RT-PCR analysis of CsCB at life-stage of C.sinensis}

$\mathrm{Cs} \mathrm{CB}$ transcrips were detected both in adults and metacercaria of $C$. sinensis (Figure 3A), and the expression level in adults was higher than that of metacercaria when normalized by $\beta$-actin (Figure 3B, $\mathrm{P}<0.05$ ).

\section{Immunohistochemical localization of $\mathrm{Cs} C B$ in $\mathrm{C}$. sinensis adults}

Using the antisera against $C s \mathrm{CB}$ as the primary antibody and fluorescence labeling IgG as the secondary antibody, immunolocalization showed that $\mathrm{Cs} C \mathrm{CB}$ distributed in the intestine of adults, while no specific fluorescence except autofluorescence was detected in adults treated with normal serum (Figure 4).

\section{Serodiagnosis of human helminthiases}

The optimal concentration of coating antigen and dilution of serum samples determined by checker board 


\begin{tabular}{|c|c|c|}
\hline & & signal peptide \\
\hline C. $\mathrm{s}$ CB & (1) & MDSIWTL IMYALLCAESFRAE YIPSFE SL SDEIVHYINHKANTTWKAAKYQRFKT ISD VRRVL \\
\hline E. $m$ CB & (1) & -----MLLQQVLMLL IAHWSSRKPHQSDRLTGIID YINNKANTTWRAGKNKRFTD ALS AKSQMGSL FNPGGSMLPT- - \\
\hline CB & (1) & ---MSWL LIFAAI W AQAKPNYKRQFEPF SDELIHYINEESGA SWKAAP STRFNNDQVKQNLGVLEETPEDRNTQ-- \\
\hline S. $\mathrm{j}$ CB & (1) & LLLCYII ILLICTLNENDARRHKHNHQPL SKELIHFINYEANTTWKAGP TRRFKTVSD IRRILGALPDPNG-EQLE-· \\
\hline H. s CB & (1) & ------MWQL WASLCCLL VLANAR SRPSFHPL SDEL VNYYN-KRNTTWQAGHNFYNVD MSYLKRLCGTFLGGPK-------- \\
\hline P. $w$ CL & (1) & -----MRLFTVSCL WWWGC AF AVVTVRVPDNAREL YEQFKRDYGKAYY ANEDDQKRFAIFKD NL VRAQQYQ TQEQGTAKYGVTQF SDL TNEEF AAMY--------LGSRIDERVDRVQLNDLQTAP ASV \\
\hline \multirow[t]{2}{*}{ T. $s$ CL } & 1) & MIVTPL LLLLLA IHSLAVWETSALL TERELSRR WAGWKL QHGRVY SGKEEAYRRGVFARRLL YIKGQNRRFNAGLE SYSTGL MPFADLES SEFSERFL GTRPESRVAGRRGR IWKALASAAGLPDTV \\
\hline & & occluding loop \\
\hline C. $\mathrm{s}$ CB & (97) & 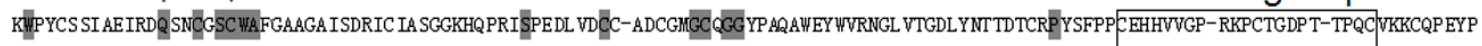 \\
\hline E. $\mathrm{m}$ CB & (93) & 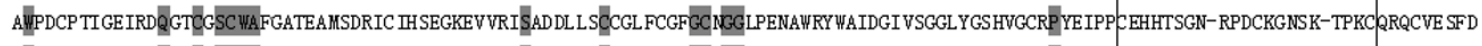 \\
\hline F.h CB & (95) & KWANCP SI SEIRDQSSCSSCWAVSSASA ITDRIC IHSNGQKKPRLSAIDI VSCC-AYCGYGCNGG IPAMSWDYWTREGVVTGGTLENPTGCLPYPFPKC SHGVVTPGLPPCPRDI YPTPKCEKKCHAGYN \\
\hline S. j CB & 104) & 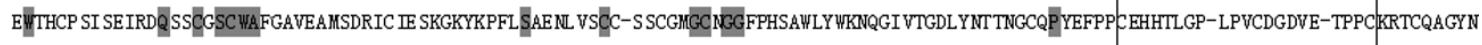 \\
\hline H. $\mathrm{S}$ CB & (89) & 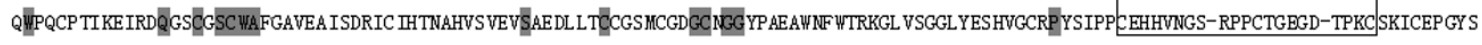 \\
\hline P.w CL & 17) & DWWREKG AVGPVEHQGSC̈GSCWAFSVTANVEGQWFLKTG--RL VSLSKRQL VDCDD--RLDHGC SGG YPPYTYKE IKRMG---GL--ELQ-SAYPYT------------------ GW----EQACRLDRS \\
\hline \multirow[t]{2}{*}{ T. s CL } & (129) & 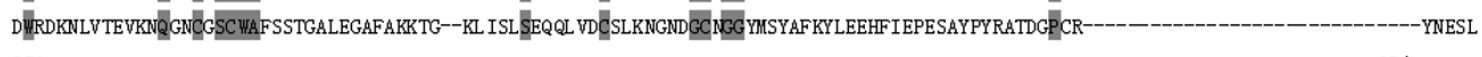 \\
\hline & & 261 \\
\hline C. $\mathrm{s}$ CB & (224) & KTYEND KWYGLKAYSIHSDQEA IMRDLMTYGPLE VDFEVYADFPSYSSGVYRHVAGGLLGGHAVRL VGWGVED GAD WUL IANSWNTD WGDGGYFKIRRG- \\
\hline E. $\mathrm{m} C B$ & 221) & GKYQAD KHFASNVYNVRASE ED IMNE IL WYGPVE ADFIVYADFL TYKSGVYQHVKGGFLGGHAVK ILGWGEENGVP YYLLANSWT \\
\hline F.h CB & $(224)$ & KTYEQD KV KGKSSYNVGGQE TD IMMIE IMKNGPVD GI FYMFED FL VYKSGI YHYTTGRL VGGHAIRVIGWGVENGVKYWWL IANSWNBG WGEKGGFRMRRG-1 \\
\hline S. j CB & (231) & VSYEND KWYGKVWYRVKSNQEA IMKELMQHGPVE VDFEVYADFPNYKSG YQHVSG ALLGGHAVRLLGWGEENNVP YYWL IANSWNTD WGDNGGYFKIIRG-K \\
\hline H. $s$ CB & (217) & PTYKQD KHYGYNSYSVSNSEKD IMAEIYKNGPVEGAFSWYSDFLL YKSG YQHVTGEMMGGHAIR ILGWGVENGTP YYUL VANSWNTD WGDNGFFKILRG-QDHCGGIE SEWVAG IPF \\
\hline P. w CL & $(213)$ & KLFAKIDD SIVLEKNEEKQA AWLAEHGPMSTCLNAGPLQFYR YGILHP SE YACSPEGL--NHAVL TVGYDTERGVPYWTVRNSWG TR WGENGYF \\
\hline T. $s$ CL & (227) & GVGTVTDIGDIPEGNETALMEAVATVGP \\
\hline \multicolumn{3}{|r|}{$\begin{array}{l}\text { Figure } 1 \text { Alignment of cathepsin B (CsCB) deduced amino acid sequence from C. sinensis and other species. The deduced amino acid } \\
\text { sequence shares } 63 \%, 52 \%, 50 \% \text { and } 53 \% \text { identity with CB of S. japonicum, H. sapiens, F. hepatica and E. multilocularis, respectively. Highly } \\
\text { conserved residues are shaded in gray. Residues of the catalytic triad }\left(\mathrm{Cys}_{116}, \mathrm{His} \mathrm{s}_{285} \text { and } \mathrm{Asn}_{305}\right) \text { are indicated with black triangles. The oxyanion } \\
\text { Gln is marked with white triangle; arrow shows cleavage point of mature enzyme, the occluding residues and hemoglobinase motif are boxed. }\end{array}$} \\
\hline
\end{tabular}

titration were $3 \mu \mathrm{g} / \mathrm{ml}$ and 1:400, respectively. The cutoff value for positive infection status in ELISA tests evaluated by receiver operating characteristic (ROC) curve was 0.47 (Figure 5). Sera from humans infected with C. sinensis showed a sensitivity of $79 \%$ by ELSA based on $\mathrm{rCs} \mathrm{CB}$ and healthy sera and sera from those infected with other helminths showed a specificity of $81 \%$ (Table 1). Both ELISA and western blotting assays showed that $\mathrm{rCs} C B$ could react with human sera from clonorchiasis, fascioliasis, schistosomiasis, paragonimiasis, cysticercosis and echinococciosis (Figure 6).

\section{Discussion}

Cathepsins in general are of interest to parasitologists, as there is considerable evidence that they play a key role in the biology of parasites [29]. In this study, a CB of C. sinensis was cloned and overexpressed in E. coli. It was classified as CB due to its sequence homology to cathepsin B protein and structure. The putative amino acid sequence shared $63 \%, 52 \%$ and $50 \%$ identities with cathepsin B from S. japonicum, H. sapiens and F. hepatica, respectively. Sequence analysis showed that $C s \mathrm{CB}$ has typical catalytic residue of cysteine, histidine and asparagine, as well an occluding loop that is the signature of cathepsin Bs [30]. A haemoglobinase motif which is shared by helminth blood-feeders could be found in this deduced sequence [31]. Since C. sinensis generally feed on bile and epithelial cells rather than blood, however, it is thought that this motif may be an important tool for identifying potential hemoglobinases and contribute to haemoglobin degradation [32]. The occluding loop is a distinctive feature of CBs; it is not only responsible for exopeptidase activity to $\mathrm{CBs}$, but also governing the $\mathrm{pH}$ dependence of auto-activation. In F. hepatica, Beckham [33] reported that recombinant FhCatB1 did not autoactivate upon secretion by yeast but could be autoactivated in a low $\mathrm{pH}$ buffer. As it stands, Cs CB may develop auto-activation in an appropriate $\mathrm{pH}$ buffer, so further studies will be carried out to investigate the autoactivation and enzyme activity of this protease.

Cathepsin B proteases of parasitic helminths such as F. hepatica and Schistosoma mansoni have been well studied. In F. hepatica, for example, there are at least 10 genes encoding $\mathrm{CB}$ being identified by using proteomics and transcriptome analysis, among which six are components of ESP of immature flukes. RNAi directed to $F h \mathrm{CB} 2$ reduced invasion of $F$. hepatica newly excysted juveniles through the intestine in vitro and vaccine with F. hepatica CB2 reduced fluke burdens and liver damage in rats following challenge, revealing that FhCB2 was a 


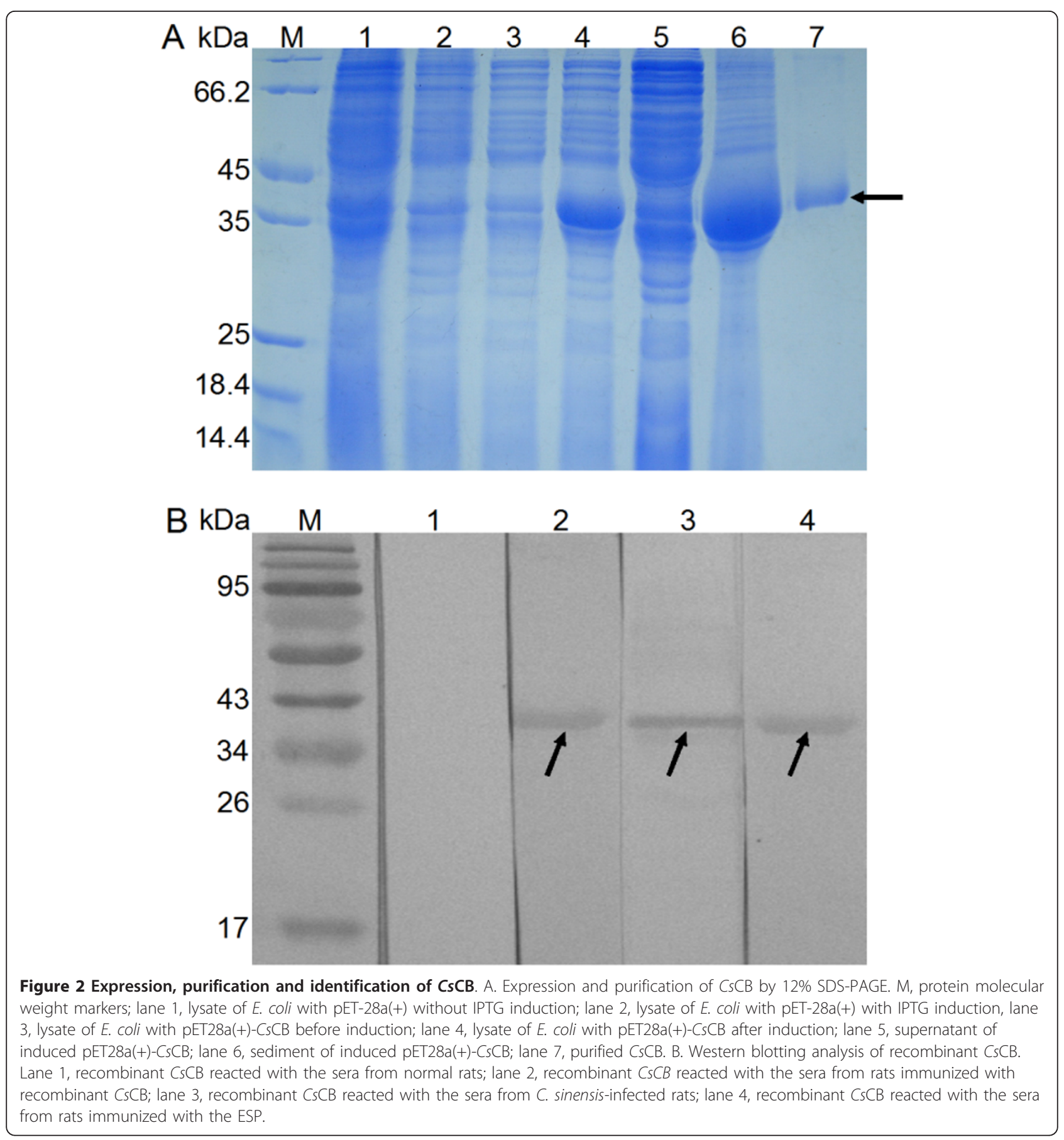

key molecule in F. hepatica biology and drug therapy [34]. In S. mansoni, SmCB1 and SmCB2 have been identified and the function of $S m C B 1$ was examined using RNAi silencing, which illustrated that $S m \mathrm{CB} 1$ played a role in nutrient acquisition $[35,36]$. Based on the key role of $\mathrm{CB}$ in the biology of parasites, we expect that $\mathrm{Cs} \mathrm{CB}$ may play the same role in nutrition intake and immune invasion of host. In multicellular parasites such as trematodes, the intestine is a major source of secreted proteases and also a place for nutrition digestion and absorption. According to results of immunolocalization, $C s \mathrm{CB}$ was distributed in the intestine of adult worm, indicating that $\mathrm{Cs} C \mathrm{CB}$ might be involved in digestion of host protein and nutrient uptake for this parasite itself. In our RT-PCR experiments, $C s \mathrm{CB}$ could be detected in both adult worm and metacercaria of $C$. sinensis. As a 


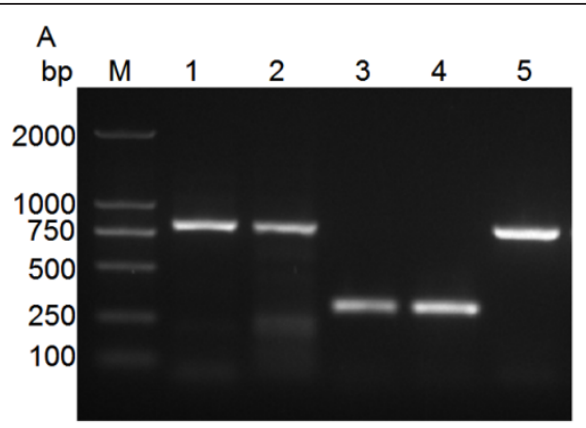

\section{B}

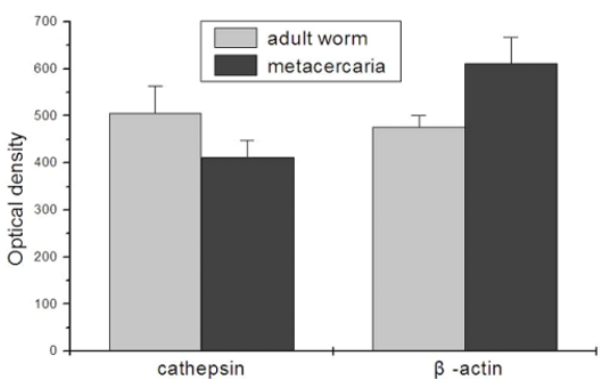

Figure 3 Transcriptional level of $C$. sinensis CB at metacercaria and adult worm. A. 1\% agarose gel. DNA marker (M), CSCB PCR products amplified from adult worm CDNA (lane 1), metacercaria CDNA (lane 2), $\beta$-actin amplified from adult worm CDNA (lane 3), metacercaria cDNA (lane 4) and CsCB PCR product amplified from recombinant CB plasmid (lane 5). B. PCR products were quantified and analyzed. PCR products were quantified by Tanon Gis software, compared normalized by C. sinensis $\beta$-actin, analyzed by Student's $t$ test (Software package SPSS16.0). Pvalue of $<0.05$ indicated statistical significance.

secreted protease, these observations suggested that Cs CB may play an important role in the biology of this parasite.

Proteases contained in ESP of parasites released to the environment, play key roles in bile duct malignancy and the subsequent development of cholangiocarcinoma $[37,38]$. Our previous studies revealed that ESP of adult C. sinensis lysophospholipase and phospholipase A2 might be pathogenic factors of human hepatic fibrosis caused by infection of $C$. sinensis [39,40], which could deepen our understanding of the pathogenesis of $C$. sinensis. CB has already been found in ESP of $C$. sinensis and some other helminths [41]. Moreover, western blotting revealed that $C s \mathrm{CB}$ was a component of ESP, and $C s \mathrm{CB}$ could react with $C$. sinensis-infected rat serum. In ELISA results, rats injected with recombinant $\mathrm{Cs} C \mathrm{~B}$ developed high antibody titers. Our results showed that $\mathrm{Cs} \mathrm{CB}$ might be involved in the pathogenesis of C. sinensis-related hepatobiliary diseases as a component of ESP with antigenicity and immunogenicity. Indeed,
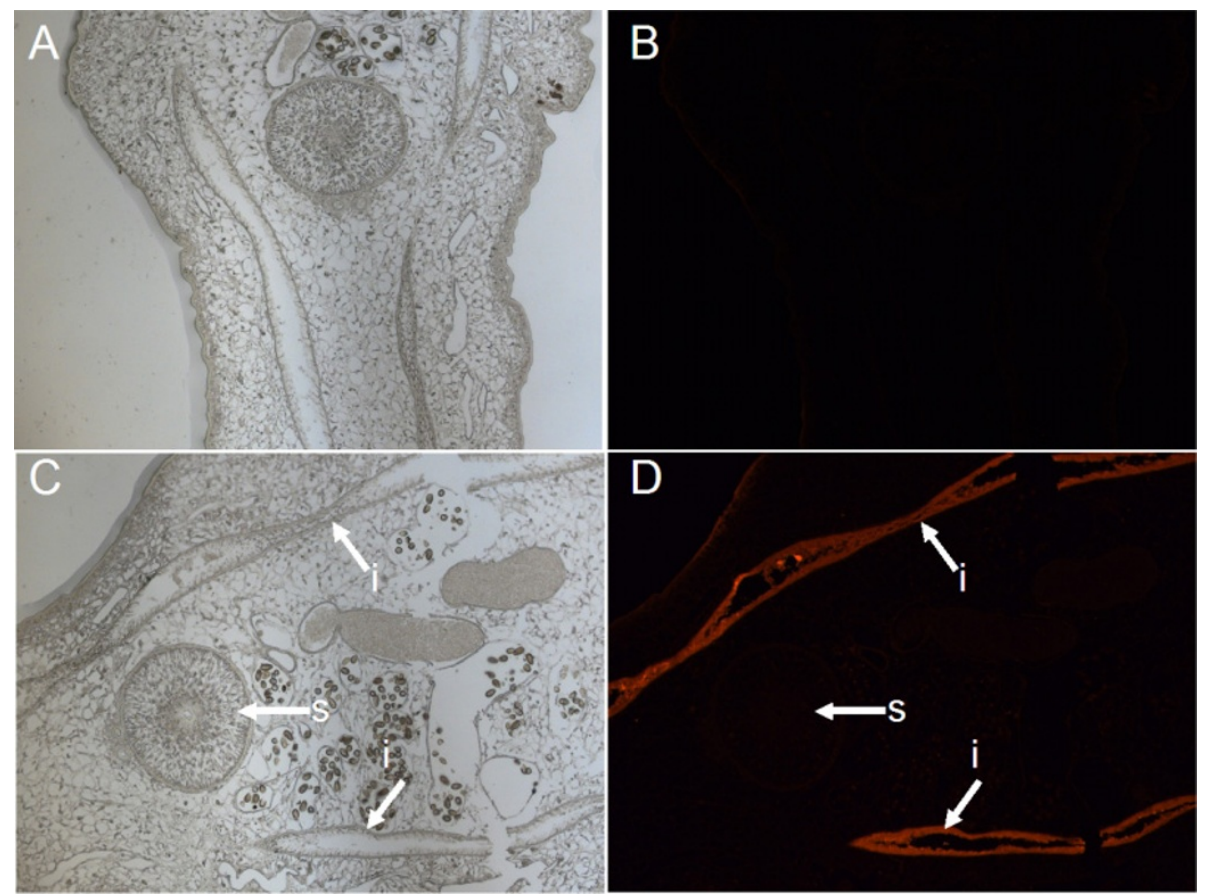

Figure 4 Immunolocalization of CsCB in adult worm of $C$. sinensis. Rat anti-CsCB serum was used as primary antibody and goat anti-rat lgG as the secondary antibody. Panel A and D show tissues of adult worm under fluorescence microscope. Panel A and C show the same part under white light. Panel A and B were the negative control treated with preimmune rat serum. i, intestine s, sucker. The images were magnified at $100 \times$ for photograph. 


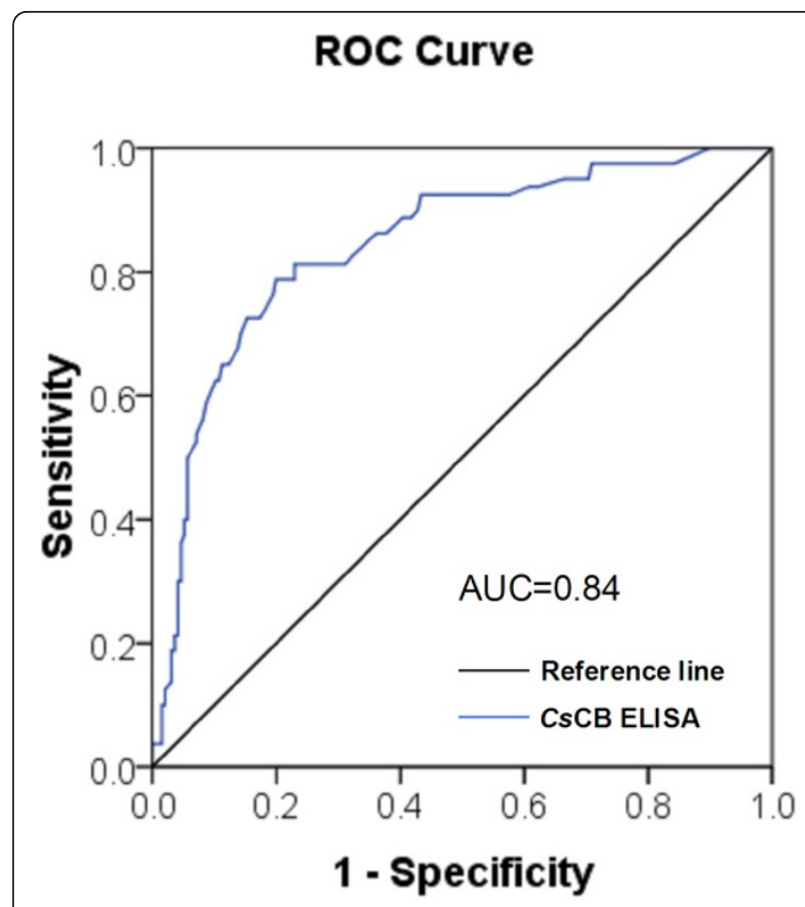

Figure 5 ROC analysis of performance of $\mathrm{rCsCB}$ as a serodiagnostic antigen. ROC curve of $\mathrm{rCSCB}$ employed as the antigen in ELISA, calculated from $\mathrm{OD}_{450}$ values of sera from parasitologically positive and negative clonorchiasis individuals. The curve was plotted between sensitivity and 1-specificity for different cut-off values of $\mathrm{OD}_{450}$. The curve showed that the optimal cut-off value at $\mathrm{OD}_{450}$ was 0.47 with the area under curve (AUC) was 0.84

Table 1 Summary of difference between rCsCB ELISA and stool examinations results.

\begin{tabular}{|c|c|c|c|}
\hline \multicolumn{4}{|l|}{ Panel A } \\
\hline \multirow[t]{2}{*}{ CsCB ELISA } & \multicolumn{3}{|c|}{ No. of samples from stool examination } \\
\hline & Negative & Positive & Total \\
\hline Negative & $158(81 \%)$ & 17 & 175 \\
\hline Positive & 38 & 63(79\%) & 101 \\
\hline Total & 196 & 80 & 276 \\
\hline \multicolumn{4}{|l|}{ Panel B } \\
\hline Parasites & \multicolumn{2}{|c|}{$\begin{array}{l}\text { No. of serum } \\
\text { samples }\end{array}$} & $\begin{array}{c}\text { No. positive of CsCB } \\
\text { ELISA }\end{array}$ \\
\hline $\begin{array}{l}\text { Echinococcus } \\
\text { multilocularis }\end{array}$ & \multicolumn{2}{|c|}{22} & $3(14 \%)$ \\
\hline Fasciola hepatica & \multicolumn{2}{|c|}{42} & $15(36 \%)$ \\
\hline Schistosoma japonicum & \multicolumn{2}{|c|}{41} & $13(32 \%)$ \\
\hline Paragonimus westermani & \multicolumn{2}{|c|}{21} & $4(19 \%)$ \\
\hline Taenia solium & \multicolumn{2}{|c|}{20} & $2(10 \%)$ \\
\hline negative & \multicolumn{2}{|c|}{50} & $1(2 \%)$ \\
\hline Total & \multicolumn{2}{|c|}{196} & $38(19 \%)$ \\
\hline
\end{tabular}

Panel A: Comparison of the rCsCB ELISA with microscopic examination of stool samples as the gold standard method for diagnosis of clonorchiasis in 276 human sera. rCsCB ELISA test showed $81 \%$ specificity and $79 \%$ sensitivity with reference to stool examination. Panel B: Number of the sera from individuals infected with other helminths used for cross-reactivity tests.
C. sinensis adults dwell in the bile duct of host, persistently released ESP resulting in mechanical damage and chemical stimulus which must have brought on infiltration of inflammatory cells surrounding bile ducts and adenomatous hyperplasia of biliary epithelia [42-44]. However, there remains much to do to elucidate the mechanism of $C$. sinensis causing hepatobiliary diseases. We have also approached the antigenicity and diagnostic value of $C s C B$ in human helminthiases. Both the ELISA and western blotting showed that $\mathrm{Cs} C \mathrm{CB}$ could react with sera from most of human helminthiases, but not with sera from healthy people. High identity in the predicted amino acid sequences of $C$. sinensis and other helminths could be responsible for the observed cross-reactivity. Though cross-reactivity existed, $C s \mathrm{CB}$ could also be applied as a diagnostic candidate of clonorchiasis since treatment with praziquantel has the same efficacy on helminths.

\section{Conclusion}

A gene encoding cathepsin B protein of adult C. sinensis was cloned and expressed for the first time. Our findings revealed that $C s \mathrm{CB}$, which is expressed in the intestine and released outside the worm as a component of ESP, may play an important role in the biology of C. sinensis. Moreover, CB may play conserved roles in helminths for the high homology analyzed by bioinformatics. Further investigations are required to characterize the conserved functions of such important protease and the role as a potential vaccine candidate against C. sinensis infection.

\section{Materials and methods}

\section{Sequence analysis of $C S C B$ gene sequence}

A complete coding sequence encoding $\mathrm{CB}$ was isolated from GenBank (Accession no. EF102086.1) in NCBI http://www.ncbi.nlm.nih.gov/, the physicochemical properties and the functional domains in deduced amino acids were predicted by proteomics tools in ExPaSy web site http://www.expasy.org/. Based on the similarity, the homologous sequences of different species, including E. multilocularis (BAJ83491.1), F. hepatica(ABU62925.1), S. japonicum (CAX71086.1), H. sapiens (NP_001899.1), Paragonimus westermani (AAB93494.1) and Taenia solium (AAS00027.1) were identified using the basic local alignment search tool (BLAST) server. Multiple sequences alignments were performed using bioinformatics analysis software Vector NTI suite 8.0.

\section{Cloning, expression, purification and refolding of $C s C B$ in} E. coli

Gene sequence encoding $\mathrm{Cs} C B$ (signal peptide excluded) was amplified from cDNA of $C$. sinensis by polymerase 


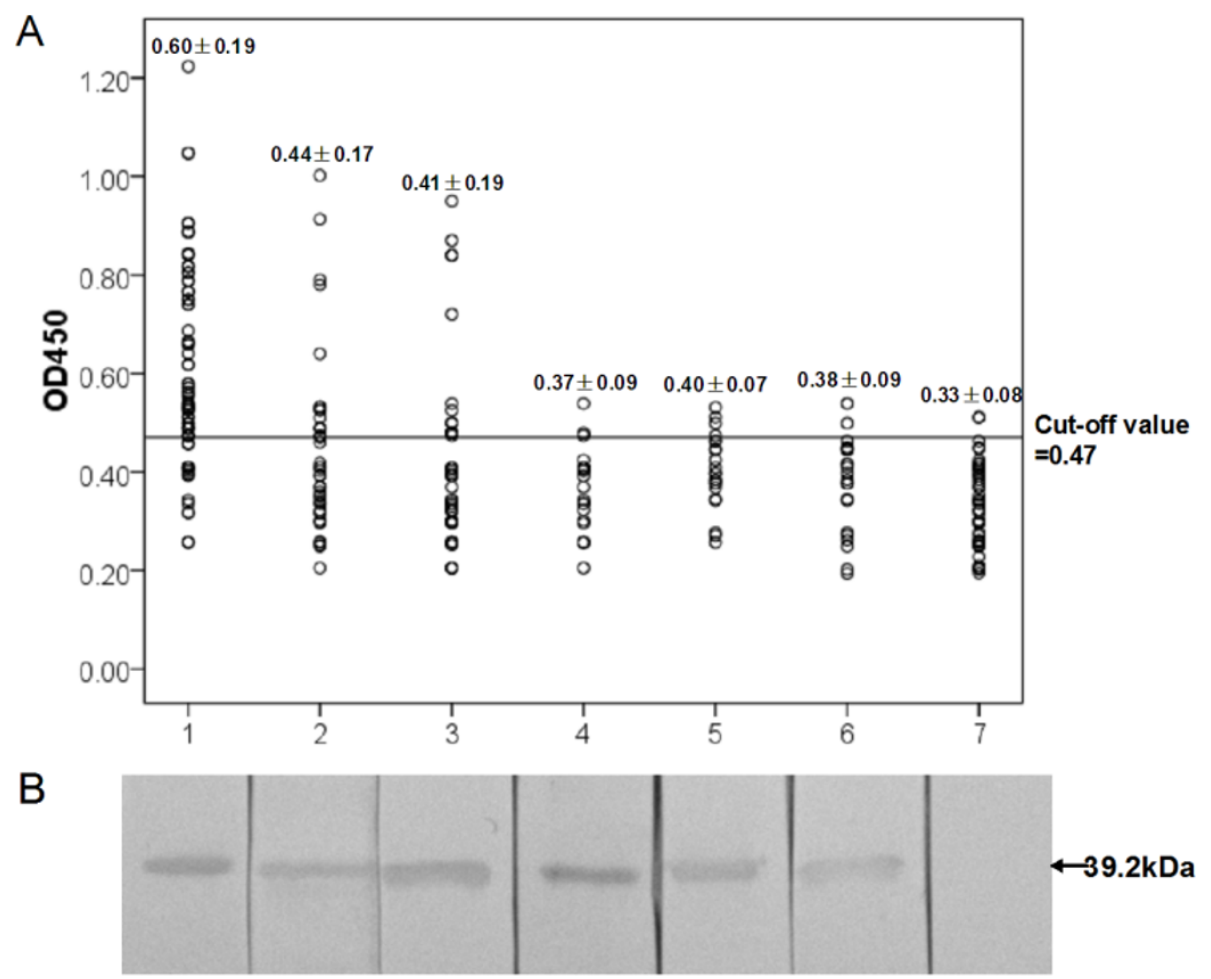

Figure 6 Immune response to human helminthiases of $\mathrm{rCsCB}$. 1-7: clonorchiasis, fascioliasis, schistosomiasis, paragonimiasis, echinococciosis, cysticercosis and healthy serum, respectively. A. Serodiagnosis of human helminthiases by ELISA(scatter plot). B. Immune reactionsshown by western blotting. The probed bands were indicated with arrow.

chain reaction (PCR) using forward primer: 5'-CGC GGATCCGAGTATATTCCATCTTTCGA-3' and the reverse primer: 5'-GTCCTCGAGTCACAGTTTTGGATGACC-3' with BamHI/XhoI restriction enzyme sites (underlined). PCR was carried out for 30 cycles at $94^{\circ} \mathrm{C}$ for $45 \mathrm{~s}, 57^{\circ} \mathrm{C}$ for $45 \mathrm{~s}$, and $72^{\circ} \mathrm{C}$ for $60 \mathrm{~s}$, and the reaction continued for $10 \mathrm{~min}$ at $72^{\circ} \mathrm{C}$ after the last cycle. Purified PCR products were cloned into the $\mathrm{His}_{6}$ tag expression vector pET-28a(+) (Novagen; USA) with corresponding incision enzymes. The recombinant plasmid was transformed into E. coli for expression and insertion confirmed by digestion with restriction enzyme and DNA sequencing. Expression of recombinant $C s \mathrm{CB}$ protein was induced by isopropyl- $\beta$-D-thiogalactoside (IPTG) at a final concentration of $0.2 \mathrm{mM}$ for $3 \mathrm{~h}$ at $30^{\circ} \mathrm{C}$. The bacterial cells were collected by centrifugation at $4^{\circ} \mathrm{C}$, and the inclusion bodies containing the recombinant fusion protein were solubilized completely with

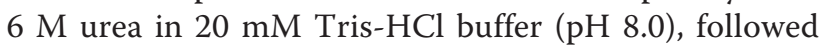
by purification with His Bind Purification kit (Novagen; USA) and elution with $150 \mathrm{mM}$ imidazole. Renaturation was carried out by stepwise diluting urea in dialysate buffer (20 mM Tris-HCl, 5 mM EDTA buffer, pH 8.0). Purified protein was analyzed by sodium dodecyl sulfate-polyacrylamide gel electrophoresis (SDS-PAGE) and stained with Coomassie blue, final recombinant protein concentration was estimated by Bradford assay using BSA method used as a standard.

\section{Semi-quantitative reverse transcription-PCR (RT-PCR) analysis of $\mathrm{CsCB}$}

In order to determine the mRNA transcriptional level of CsCB in various stages of the parasite, total RNA of adult worms and metacercariae were extracted and quantitated by nucleic acid/protein analyzer (Beckman Coulter; USA). Reverse transcription reactions were carried out by transforming equal amounts of total RNA $(1 \mu \mathrm{g}$ each) to cDNA using RT-PCR Kit (TaKaRa; PR China). RT-PCR experiments were employed to amplify the transcripts of $\mathrm{Cs} C \mathrm{~B}$ from cDNA of adult worms and metacercariae, respectively, and C. sinensis $\beta$-actin (GenBank accession no. EU109284) was used as a positive control. The forward and reverse primer for CsCB were 5'-GGATTCGGCCTGGAAAAAC-3', 5'-CAGTTTTGGATGACCAGCAT-3' and for $\beta$-actin were 5 '-GGTGACGCTGAAGTATCCTATTGA-3', 5'-CCAAAGCATAGCCCTCGTAGAT-3', respectively. The programs for PCR were the same as described above. PCR products from two life stages were quantified by Tanon Gis software (Tanon 4100; PR China) normalized by $C$. sinensis $\beta$-actin and analyzed by 
Student's $t$ test (Software package SPSS16.0), $P$-value of $<$ 0.05 indicated statistical significance.

\section{Preparation for the antisera of recombinant protein and C. sinensis excretory/secretory product (ESP)}

Living adults of $C$. sinensis were collected and cultured in RPMI-1640 (Gibco; USA) at $37^{\circ} \mathrm{C}$ under $5 \% \mathrm{CO}_{2}$ for $6 \mathrm{~h}$. The culture was centrifuged at $12,000 \times \mathrm{g}$ at $4^{\circ} \mathrm{C}$ for $30 \mathrm{~min}$ to remove insoluble debris. The supernatant was dialyzed in PBS for $12 \mathrm{~h}$ and concentrated with sucrose. Six-week-old male Sprague-Dawley rats were purchased for animal experiments under the Guide for the Care and Use of Laboratory Animals. Both the recombinant $\mathrm{CB}$ and ESP were emulsified with complete Freund's adjuvant and immunized subcutaneously to SD rats. Each rat was given $200 \mu \mathrm{g} r \mathrm{CsCB}$ or ESP at the first injection, and $100 \mu \mathrm{g}$ protein (emulsified with incomplete Freund's adjuvant) was given for 2 booster injections at 2-week intervals; antisera were collected before each injection and serum antibody responses to $\mathrm{r} C s \mathrm{CB}$ and ESP were tested by ELISA.

\section{SDS-PAGE and western blotting}

The recombinant protein (1 $\mu$ g per lane) was subjected to SDS-PAGE and electrotransferred onto polyvinylidene difluoride membrane (PVDF, Whatman; USA) at $100 \mathrm{v}$ for $1 \mathrm{~h}$. The membrane was blocked with $5 \%$ skim milk in phosphate buffered saline tween-20 (PBST, pH 7.4) at $37^{\circ} \mathrm{C}$ for $2 \mathrm{~h}$, washed 5 times with PBST, then incubated with different antisera (antisera against the recombinant Cs $\mathrm{CB}$ protein, antisera against the ESP, sera from C. sinensis-infected rats and normal rats, respectively, 1:200 dilutions for all sera) at $37^{\circ} \mathrm{C}$ for $2 \mathrm{~h}$. After washing, the membrane was incubated with rabbit anti-rat IgG HRP-conjugated horse radish peroxidase $(1: 2,000$ dilution; Boster; PR China) at $37^{\circ} \mathrm{C}$ for $1 \mathrm{~h}$. Diaminobenzidine (DAB) substrate solution (Invitrogen, USA) was used to visualize the reaction according to the manufacturer's instructions.

\section{Immunolocalization of $\mathrm{Cs} C B$ protein in $C$. sinensis adult worm}

C. sinensis adult worms fixed with $10 \%$ neutral formalin were embedded with paraffin and sliced into 3-5 $\mu \mathrm{m}$ thickness. After deparaffinating with dimethyl benzene and gradient alcohol, all sections were blocked with normal goat serum at $4^{\circ} \mathrm{C}$ overnight, then incubated with rat anti-CsCB serum for $2 \mathrm{~h}$ at room temperature (RT), the sera from normal rats were used as negative control, the serum was diluted at 1: 200 for all sections. The sections were subsequently incubated with goat anti-rat IgG labeled with red-fluorescent Cy3 (1: 400 dilutions with $0.1 \%$ BSA in PBS, Jackson, USA) for $1 \mathrm{~h}$ at RT in dark and imaged using fluorescent microscope (ZEISS; Germany).

\section{Source of serum samples}

A total of 276 human serum samples were employed in order to approach the antigenicity and diagnostic value of $\mathrm{Cs} \mathrm{CB}$ in human helminthiases. 80 sera from clonorchiasis patients were collected from endemic areas in Guangxi Province and were egg-positive proved by microscopic examination of stool samples. Other human sera including single infection of E. multilocularis (22), F. hepatica (42), S. japonicum (41), P. westermani (21), T. solium (20) and 50 samples of serum from healthy humans were provided and diagnosed by Centers for Disease Control and Prevention of Nanning, Jiangsu, Gansu and Fujian provinces. Sera were retrieved and stored in aliquots at $-20^{\circ} \mathrm{C}$ until use.

\section{Serodiagnosis of human helminthiases by ELISA and western blotting}

The optimal antigen concentration and serum dilution required for ELISA were determined by checker board titration. Briefly, 96-well microtiter plates (Costar, USA) were coated with $100 \mu \mathrm{l} 1 \mu \mathrm{g} / \mathrm{ml}, 3 \mu \mathrm{g} / \mathrm{ml}, 5 \mu \mathrm{g} / \mathrm{ml}$, $7 \mu \mathrm{g} / \mathrm{ml} \mathrm{rCsCB}$ (in $0.05 \mathrm{~mol} / \mathrm{l} \mathrm{NaHCO} 3$ buffer, $\mathrm{pH}$ 9.6) and incubated at $4{ }^{\circ} \mathrm{C}$ overnight. After three washings with PBST, the microplates were blocked with 5\% skimmed milk ( $w / v$, in PBST containing 0.1\% BSA) for $2 \mathrm{~h}$ at $37^{\circ} \mathrm{C}$. Following another washing procedure, the plates were incubated with human helminthiases sera (1:50, 1:100, 1:200, 1:400 dilutions for each coating concentration in PBST containing 0.1\% BSA) for $2 \mathrm{~h}$ at $37^{\circ} \mathrm{C}$. Goat anti-human IgG (1:10,000 dilutions in $0.1 \%$ BSA-PBST recommended by producer; Invitrogen, USA) were employed as the secondary antibody. Subsequent reactions were developed with 3', 3', 5', 5'-tetramethyl benzidine (TMB; BD Biosciences; USA) and stopped with $2 \mathrm{M} \mathrm{H}_{2} \mathrm{SO}$. All assays were tested in triplicate and repeated twice. The absorbance value was measured at $450 \mathrm{~nm}$.

In western blotting assay, $\mathrm{r} C s \mathrm{CB}$ was subjected to $12 \%$ SDS-PAGE and electrotransferred onto PVDF membrane (Whatman; USA). The membrane was incubated with different human helminthiases sera (clonorchiasis, echinococciosis, fascioliasis, schistosomiasis, paragonimiasis, and cysticercosis, respectively) which showed high $\mathrm{OD}_{450}$ values by ELISA test at $37^{\circ} \mathrm{C}$ for $2 \mathrm{~h}$, human healthy serum was used as negative control, all sera were 1:400 diluted in PBST containing 0.1\% BSA. Goat anti-human IgG HRP-conjugated horse radish peroxidase (1:2,000 dilution; Boster; PR China) was the secondary antibody to react with the membrane and $\mathrm{DAB}$ substrate solution was used to visualize the reaction. 


\section{Statistical analysis}

Software package SPSS16.0 was used in the present study for all statistical analysis. Briefly, Student's $t$ test was used to analyze the measurement data among groups. $P$ value of $<0.05$ was considered statistically significant. The optimal cut-off value was calculated based on ROC curve analysis which correlated with sensitivity and 1-specificity [45]. ROC curve, area under the curve (AUC) and scatter plot were carried out using SPSS16.0. The sensitivity and specificity were calculated using microscopic examination of stool samples as gold standard method.

\section{Ethical approval}

Centers for Disease Control and Prevention of Nanning, Jiangsu, Gansu and Fujian provinces granted ethical approval for human sera used in the present study. All animal experiments were approved by institute's ethical committee of Sun Yat-sen University.

\section{Acknowledgements}

This work is supported by the National S \& T Major Program (Grant No. 2008ZX10004-011) and Development Program of China (973 program; no. 2010CB530000).

\section{Author details \\ ${ }^{1}$ Department of Parasitology, Zhongshan School of Medicine, Sun Yat-sen University, Guangzhou 510080, People's Republic of China. ${ }^{2}$ Key Laboratory for Tropical Diseases Control, Sun Yat-sen University, Ministry of Education, Guangzhou 510080, People's Republic of China. ${ }^{3}$ Department of Gynecology and Pediatrics, Nursing School, Guangdong Medical College, Dongguan, 523808, PR China.}

\section{Authors' contributions}

WJC, XYW and XBY conceived and designed the experiments; WJC, XYW, $X R L, C H Z, X L L, C H D, H L L, J T M, Y X F$ and $C L$ performed the experiments; WJC, $X Y W, X R L$ and $X L L$ analyzed the data. All authors read and approved the final manuscript.

\section{Competing interests}

The authors declare that they have no competing interests.

Received: 23 March 2011 Accepted: 27 July 2011

Published: 27 July 2011

\section{References}

1. Lun ZR, Gasser RB, Lai DH, Li AX, Zhu XQ, Yu XB, Fang YY: Clonorchiasis: a key foodborne zoonosis in China. Lancet Infect Dis 2005, 5:31-41.

2. Chai JY, Darwin Murrell K, Lymbery AJ: Fish-borne parasitic zoonoses: status and issues. Int J Parasitol 2005, 35:1233-1254.

3. Sripa B: Pathobiology of opisthorchiasis: an update. Acta Trop 2003, 88:209-220.

4. Shin HR, Oh JK, Masuyer E, Curado MP, Bouvard V, Fang YY, Wiangnon S, Sripa B, Hong ST: Epidemiology of cholangiocarcinoma: an update focusing on risk factors. Cancer Sci 2010, 101:579-585.

5. Lee M, Chung YB, Lee SK, Chung BS, Li S, Choi MH, Hong ST: The identification of a Clonorchis sinensis gene encoding an antigenic egg protein. Parasitol Res 2005, 95:224-226.

6. Zhou XN, Lv S, Yang GJ, Kristensen TK, Bergquist NR, Utzinger J, Malone JB: Spatial epidemiology in zoonotic parasitic diseases: insights gained at the 1st International Symposium on Geospatial Health in Lijiang, China, 2007. Parasit Vectors 2009, 2:10.

7. Mesplet M, Echaide I, Dominguez M, Mosqueda JJ, Suarez CE, Schnittger L, Florin-Christensen M: Bovipain-2, the falcipain-2 ortholog, is expressed in intraerythrocytic stages of the tick-transmitted hemoparasite Babesia bovis. Parasit Vectors 2010, 3:113.

8. Cruz CE, Fogaca AC, Nakayasu ES, Angeli CB, Belmonte R, Almeida IC, Miranda A, Miranda MT, Tanaka AS, Braz GR, et al: Characterization of proteinases from the midgut of Rhipicephalus (Boophilus) microplus involved in the generation of antimicrobial peptides. Parasit Vectors 2010, 3:63.

9. Sojka D, Franta Z, Horn M, Hajdusek O, Caffrey CR, Mares M, Kopacek P: Profiling of proteolytic enzymes in the gut of the tick Ixodes ricinus reveals an evolutionarily conserved network of aspartic and cysteine peptidases. Parasit Vectors 2008, 1:7.

10. Sajid M, McKerrow JH: Cysteine proteases of parasitic organisms. Mol Biochem Parasitol 2002, 120:1-21.

11. Dalton JP, Neill SO, Stack C, Collins P, Walshe A, Sekiya M, Doyle S, Mulcahy G, Hoyle D, Khaznadji E, et al: Fasciola hepatica cathepsin L-like proteases: biology, function, and potential in the development of first generation liver fluke vaccines. Int J Parasitol 2003, 33:1173-1181.

12. Meemon K, Grams R, Vichasri-Grams S, Hofmann A, Korge G, Viyanant V, Upatham ES, Habe S, Sobhon P: Molecular cloning and analysis of stage and tissue-specific expression of cathepsin B encoding genes from Fasciola gigantica. Mol Biochem Parasitol 2004, 136:1-10.

13. Na BK, Kim SH, Lee EG, Kim TS, Bae YA, Kang I, Yu JR, Sohn WM, Cho SY, Kong Y: Critical roles for excretory-secretory cysteine proteases during tissue invasion of Paragonimus westermani newly excysted metacercariae. Cell Microbiol 2006, 8:1034-1046.

14. Loukas A, Bethony JM, Williamson AL, Goud GN, Mendez S, Zhan B, Hawdon JM, Elena Bottazzi M, Brindley PJ, Hotez PJ: Vaccination of dogs with a recombinant cysteine protease from the intestine of canine hookworms diminishes the fecundity and growth of worms. J Infect Dis 2004, 189:1952-1961.

15. Abdulla MH, Lim KC, Sajid M, McKerrow JH, Caffrey CR: Schistosomiasis mansoni: novel chemotherapy using a cysteine protease inhibitor. PLOS Med 2007, 4:e14.

16. Behnke JM, Buttle DJ, Stepek G, Lowe A, Duce IR: Developing novel anthelmintics from plant cysteine proteinases. Parasit Vectors 2008, 1:29.

17. Kang JM, Bahk YY, Cho PY, Hong SJ, Kim TS, Sohn WM, Na BK: A family of cathepsin $\mathrm{F}$ cysteine proteases of Clonorchis sinensis is the major secreted proteins that are expressed in the intestine of the parasite. $\mathrm{Mol}$ Biochem Parasitol 2010, 170:7-16.

18. Ju JW, Joo HN, Lee MR, Cho SH, Cheun HI, Kim JY, Lee YH, Lee K, Sohn WM, Kim DM, et al: Identification of a serodiagnostic antigen, legumain, by immunoproteomic analysis of excretory-secretory products of Clonorchis sinensis adult worms. Proteomics 2009, 9:3066-3078.

19. Li Y, Hu X, Liu X, Xu J, Hu F, Ma C, Yu X: Molecular cloning and analysis of stage and tissue-specific expression of Cathepsin L-like protease from Clonorchis sinensis. Parasitol Res 2009, 105:447-452.

20. Lee JS, Kim IS, Sohn WM, Lee J, Yong TS: Vaccination with DNA encoding cysteine proteinase confers protective immune response to rats infected with Clonorchis sinensis. Vaccine 2006, 24:2358-2366.

21. Li S, Chung YB, Chung BS, Choi MH, Yu JR, Hong ST: The involvement of the cysteine proteases of Clonorchis sinensis metacercariae in excystment. Parasitol Res 2004, 93:36-40.

22. Kang TH, Yun DH, Lee EH, Chung YB, Bae YA, Chung JY, Kang I, Kim J, Cho SY, Kong Y: A cathepsin F of adult Clonorchis sinensis and its phylogenetic conservation in trematodes. Parasitology 2004, 128:195-207.

23. Morphew RM, Wright HA, LaCourse EJ, Woods DJ, Brophy PM: Comparative proteomics of excretory-secretory proteins released by the liver fluke Fasciola hepatica in sheep host bile and during in vitro culture ex host. Mol Cell Proteomics 2007, 6:963-972.

24. Nagano I, Pei F, Wu Z, Wu J, Cui H, Boonmars T, Takahashi Y: Molecular expression of a cysteine proteinase of Clonorchis sinensis and its application to an enzyme-linked immunosorbent assay for immunodiagnosis of clonorchiasis. Clin Diagn Lab Immunol 2004, 11:411-416.

25. Na BK, Lee HJ, Cho SH, Lee HW, Cho JH, Kho WG, Lee JS, Song KJ, Park PH, Song CY, Kim TS: Expression of cysteine proteinase of Clonorchis sinensis and its use in serodiagnosis of clonorchiasis. J Parasitol 2002, 88:1000-1006.

26. Cornelissen JB, Gaasenbeek CP, Borgsteede FH, Holland WG, Harmsen MM, Boersma WJ: Early immunodiagnosis of fasciolosis in ruminants using recombinant Fasciola hepatica cathepsin L-like protease. Int J Parasitol 2001, 31:728-737. 
27. Carnevale S, Rodriguez MI, Guarnera EA, Carmona C, Tanos T, Angel SO: Immunodiagnosis of fasciolosis using recombinant procathepsin L cystein proteinase. Diagn Microbiol Infect Dis 2001, 41:43-49.

28. Sripa J, Brindley PJ, Sripa B, Loukas A, Kaewkes S, Laha T: Evaluation of liver fluke recombinant cathepsin B-1 protease as a serodiagnostic antigen for human opisthorchiasis. Parasitol Int 2011.

29. McKerrow JH, Caffrey C, Kelly B, Loke P, Sajid M: Proteases in parasitic diseases. Annu Rev Pathol 2006, 1:497-536.

30. Illy C, Quraishi O, Wang J, Purisima E, Vernet T, Mort JS: Role of the occluding loop in cathepsin B activity. J Biol Chem 1997, 272:1197-1202.

31. Baig S, Damian RT, Peterson DS: A novel cathepsin B active site motif is shared by helminth bloodfeeders. Exp Parasitol 2002, 101:83-89.

32. Ranjit N, Zhan B, Stenzel DJ, Mulvenna J, Fujiwara R, Hotez PJ, Loukas A: A family of cathepsin $B$ cysteine proteases expressed in the gut of the human hookworm, Necator americanus. Mol Biochem Parasitol 2008, 160:90-99.

33. Beckham SA, Law RH, Smooker PM, Quinsey NS, Caffrey CR, McKerrow JH, Pike RN, Spithill TW: Production and processing of a recombinant Fasciola hepatica cathepsin B-like enzyme (FhcatB1) reveals potential processing mechanisms in the parasite. Biol Chem 2006, 387:1053-1061.

34. McGonigle L, Mousley A, Marks NJ, Brennan GP, Dalton JP, Spithill TW, Day TA, Maule AG: The silencing of cysteine proteases in Fasciola hepatica newly excysted juveniles using RNA interference reduces gut penetration. Int J Parasitol 2008, 38:149-155.

35. Correnti JM, Brindley PJ, Pearce EJ: Long-term suppression of cathepsin B levels by RNA interference retards schistosome growth. Mol Biochem Parasitol 2005, 143:209-215.

36. Skelly PJ, Da'dara A, Harn DA: Suppression of cathepsin B expression in Schistosoma mansoni by RNA interference. Int J Parasitol 2003, 33:363-369.

37. Pak JH, Kim DW, Moon JH, Nam JH, Kim JH, Ju JW, Kim TS, Seo SB: Differential gene expression profiling in human cholangiocarcinoma cells treated with Clonorchis sinensis excretory-secretory products. Parasitol Res 2009, 104:1035-1046.

38. Kim YJ, Choi MH, Hong ST, Bae YM: Resistance of cholangiocarcinoma cells to parthenolide-induced apoptosis by the excretory-secretory products of Clonorchis sinensis. Parasitol Res 2009, 104:1011-1016.

39. Hu F, Hu X, Ma C, Zhao J, Xu J, Yu X: Molecular characterization of a novel Clonorchis sinensis secretory phospholipase $\mathrm{A}(2)$ and investigation of its potential contribution to hepatic fibrosis. Mol Biochem Parasitol 2009, 167:127-134

40. Ma C, Hu X, Hu F, Li Y, Chen X, Zhou Z, Lu F, Xu J, Wu Z, Yu X: Molecular characterization and serodiagnosis analysis of a novel lysophospholipase from Clonorchis sinensis. Parasitol Res 2007, 101:419-425.

41. Smooker PM, Jayaraj R, Pike RN, Spithill TW: Cathepsin B proteases of flukes: the key to facilitating parasite control? Trends Parasitol 2010, 26:506-514.

42. Wang X, Liang C, Chen W, Fan Y, Hu X, Xu J, Yu X: Experimental model in rats for study on transmission dynamics and evaluation of Clonorchis sinensis infection immunologically, morphologically, and pathologically. Parasitol Res 2009, 106:15-21.

43. Sripa B, Kaewkes S, Sithithaworn P, Mairiang E, Laha T, Smout M, Pairojkul C, Bhudhisawasdi V, Tesana S, Thinkamrop B, et al: Liver fluke induces cholangiocarcinoma. PLoS Med 2007, 4:e201.

44. Olnes MJ, Erlich R: A review and update on cholangiocarcinoma. Oncology 2004, 66:167-179.

45. Bon B, Houze S, Talabani H, Magne D, Belkadi G, Develoux M, Senghor Y, Chandenier J, Ancelle T, Hennequin C: Evaluation of a rapid enzymelinked immunosorbent assay for diagnosis of strongyloidiasis. J Clin Microbiol 2010, 48:1716-1719.

doi:10.1186/1756-3305-4-149

Cite this article as: Chen et al:: Molecular characterization of cathepsin $\mathrm{B}$ from Clonorchis sinensis excretory/secretory products and assessment of its potential for serodiagnosis of clonorchiasis. Parasites \& Vectors 2011 4:149.

\section{Submit your next manuscript to BioMed Central and take full advantage of:}

- Convenient online submission

- Thorough peer review

- No space constraints or color figure charges

- Immediate publication on acceptance

- Inclusion in PubMed, CAS, Scopus and Google Scholar

- Research which is freely available for redistribution

Submit your manuscript at www.biomedcentral.com/submit
Biomed Central 